\title{
Structure and Electrochemical Properties of a Mechanochemically Processed Silicon and Oxide-Based Nanoscale Composite as an Active Material for Lithium-Ion Batteries
}

\author{
Norihiro Shimoi and Kazuyuki Tohji \\ Graduate School of Environmental Studies, Tohoku University, 6-6-20 Aoba, Aramaki, Aoba-ku, Sendai 980-8579, Japan \\ Correspondence should be addressed to Norihiro Shimoi; norihiro.shimoi.c8@tohoku.ac.jp
}

Received 24 December 2016; Accepted 23 February 2017; Published 9 March 2017

Academic Editor: Cheng Yan

Copyright (c) 2017 Norihiro Shimoi and Kazuyuki Tohji. This is an open access article distributed under the Creative Commons Attribution License, which permits unrestricted use, distribution, and reproduction in any medium, provided the original work is properly cited.

\begin{abstract}
$\mathrm{Si}$ is essential as an active material in Li-ion batteries because it provides both high charge and optimal cycling characteristics. A composite of $\mathrm{Si}$ particles, $\mathrm{Cu}$ particles, and pure $\mathrm{H}_{2} \mathrm{O}$ was realized to serve as an anode active material and optimize the chargedischarge characteristics of Li-ion batteries. The composite was produced by grinding using a planetary ball mill machine, which allowed for homogenous dispersion of nanoscale $\mathrm{Cu}_{3} \mathrm{Si}$ as $\mathrm{Si}-\mathrm{Cu}$ alloy grains and nanoscale $\mathrm{Si}$ grains in each poly-Si particle produced. Furthermore, some Si particles were oxidized by $\mathrm{H}_{2} \mathrm{O}$, and oxidized $\mathrm{Si}$ was distributed throughout the composite, mainly as silicon monoxide. As a result, each Si particle included silicon monoxide and conductive $\mathrm{Cu}_{3} \mathrm{Si} \mathrm{materials,} \mathrm{allowing} \mathrm{for} \mathrm{effective}$ optimization of the recharging and charge-discharge characteristics. Thus, a new and simple process was realized for synthesizing a Si active material composited with silicon oxides, including silicon monoxide. This Si-rich conductive material is suitable as an anode for Li-ion batteries with high charge and optimized cycling properties.
\end{abstract}

\section{Introduction}

Owing to its high theoretical Li storage potential of about $4000 \mathrm{mAh}^{-1}$ [1], Si is one of the most attractive anode materials for Li-ion batteries (LIBs). However, Si undergoes frequent drastic changes in volume during charge-discharge cycling, causing degradation of Si materials and drastically decreasing ionic and electronic conductivities, which has prevented $\mathrm{Si}$ anodes from being utilized in Li-ion secondary batteries [2]. To overcome this problem, various modifications, such as the use of nanostructured Si anodes, the synthesis of composites with other materials, and the use of carbon coatings, have been suggested [3-5]. The use of $\mathrm{Si}$ monoxide as an alternative anode material has been proposed [6-11], as Si monoxide exhibits little change in volume and high conductivity. However, the capacity of Si monoxide is only about $1200 \mathrm{mAh} \mathrm{g}^{-1}$, which is lower than that of other potential materials $[12,13]$. Numerous attempts have been made to find ways to compensate for this by combining $\mathrm{Si}$ monoxide with other materials [14-17].

This study considers a technique that maintains the high ionic and electronic conductivities of Si by preventing cracking during volume changes, with as little effect as possible on the capacity of the material. Namely, particles of an active material based on $\mathrm{Si}$ were formed into the core of a suitable conductive material and the Si crystal structure was controlled by compositing $\mathrm{Si}$ particles with other materials. To achieve this, we designed a composition including $\mathrm{Si}$, Si oxide, and a conductive material, which could be employed as an anode electrode in LIBs. In this study, to synthesize a composite of $\mathrm{Si}$ and other materials, we used a grinding process to combine $\mathrm{Si}$ with $\mathrm{H}_{2} \mathrm{O}$ as an oxidant and $\mathrm{Cu}$ as a conductive material. The grinding method was considered the most likely method to achieve a composite containing a homogeneous distribution of nanoscale $\mathrm{Si}$ and conductive materials. It was expected that a Si oxide with a 


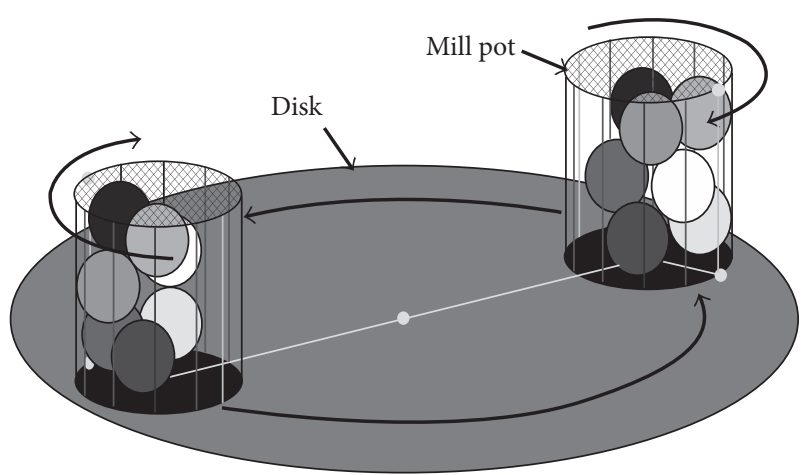

Figure 1: Schematic of the mechanics of a planetary ball mill.

low $\mathrm{Si}$ oxidation number would be formed by grinding with $\mathrm{H}_{2} \mathrm{O}$, resulting in the transfer of oxygen atoms the $\mathrm{Si}$ and $\mathrm{Si}$ particles. Moreover, a composite material containing Si oxide, $\mathrm{Cu}$, and $\mathrm{Si}$ is expected to yield good performance with regard to charge-discharge characteristics.

In this study, we developed a grinding method in which Si particles (average diameter of $4 \mu \mathrm{m}$, purity of $99.999 \%$; Kojundo Chemistry Laboratory Co., Ltd., Japan) and $\mathrm{Cu}$ particles (average diameter of $4 \mu \mathrm{m}$; Kojundo Chemistry Laboratory Co., Ltd., Japan) as a conductive material were ground with pure $\mathrm{H}_{2} \mathrm{O}$ in the mill pots of a planetary ball mill (Fritsch Pulverisette-7) to produce a composite material. A mixture of approximately $2 \mathrm{~g}$ was put in a zirconia mill pot with a $45 \mathrm{~cm}^{3}$ inner volume with 7 zirconia balls of $15 \mathrm{~mm}$ diameter and subjected to grinding using the planetary ball mill, as shown in Figure 1, at approximately $600 \mathrm{rpm}$ in air. The mill pots rotated individually on a rotating disk. The crushing conditions were varied by changing the amounts of $\mathrm{Cu}$, pure $\mathrm{H}_{2} \mathrm{O}$, and $\mathrm{Si}$ particles, as well as the grinding time. Table 1 shows the amounts of $\mathrm{Si}, \mathrm{H}_{2} \mathrm{O}$, and $\mathrm{Cu}$ used in this study to prepare composites by grinding. The " $X$ " values in Table 1 indicate the ratio of oxide atoms in the prepared composite relative to $\mathrm{Si}$. The amount of $\mathrm{Cu}$ was constant based on the conditions for grinding $\mathrm{Si}$ and $\mathrm{CuO}$ [18]. Crushing and reconstruction of materials in the mill pot was expected to result in the formation of a composite containing $\mathrm{Si}, \mathrm{Cu}$, and oxidized species. Oxidation reactions that result in the transfer of an oxygen atom from $\mathrm{H}_{2} \mathrm{O}$ to $\mathrm{Si}$ would produce a $\mathrm{Si}$ suboxide in the composite with $\mathrm{Si}$ and $\mathrm{Cu}$. Further, residual $\mathrm{Cu}$ can serve as an electrically conductive material. Such composites synthesized from $\mathrm{Si}, \mathrm{H}_{2} \mathrm{O}$, and $\mathrm{Cu}$ could then be employed as the active material in LIB anodes.

1.1. Characterization of Composite Material. Scanning electron microscopy (SEM; Hitachi High-Technologies Corporation, Japan) was used to examine the morphology of the composite particles. A composite-coated electrode was cut using a Ga focused ion beam (FIB; Hitachi High-Technologies Corporation, Japan) at an accelerating voltage of $5 \mathrm{kV}$. Scanning transmission electron microscopy (STEM; Hitachi HighTechnologies Corporation, Japan) was carried out at an accelerating voltage of $200 \mathrm{kV}$ to image cross sections of the electrode. The atomic distribution of $\mathrm{Si}$, oxides, and $\mathrm{Cu}$ was measured using energy dispersive X-ray spectroscopy (EDX; Hitachi High-Technologies Corporation, Japan). The crystallization state of the ground composite was examined using X-ray diffraction (XRD; Rigaku Co. Japan). Electron energy-loss spectroscopy (EELS; Hitachi High-Technologies Corporation, Japan) at $200 \mathrm{kV}$ was used to measure the distribution of oxides in the composite at a resolution of $0.5 \mathrm{eV}$. The EELS map was constructed from spectral images in the energy-loss region of $200-2200 \mathrm{eV}$, as detected using multiple charge-coupled devices. High-resolution Si2p X-ray photoelectron spectroscopy (XPS; Bruker) with a monochromatic AlK $\alpha$ X-ray source, an analysis range of $0.62 \mathrm{~mm}$ in diameter, and a detection angle of $45^{\circ}$ was used to determine the oxidation number of $\mathrm{Si}$ in the composite particles. The composite particles were ground uniformly on a XPS sample holder, and measurements were obtained for the flattest section.

1.2. Anode Preparation and Electrochemical Testing. Anode electrodes for LIBs were prepared using the composites of $\mathrm{Si}$, $\mathrm{H}_{2} \mathrm{O}$, and $\mathrm{Cu}$ as follows. Composite particles were mixed with a binder composed of polyamic acid (Ube-Kousan KK, Japan) and acetylene black (AB; Denkikagaku Kogyo KK, Japan) as a conductive material in a 1-methyl-2-pyrrolidone (NMP) solution. The weight ratio of composite particles : binder: $\mathrm{AB}$ was $70: 20: 10$. To form electrodes, this slurry was cast onto a $\mathrm{Cu}$ foil and dried at $70^{\circ} \mathrm{C}$ for $30 \mathrm{~min}$ in air. The coated electrodes were cut to a size of $10 \mathrm{~mm} \phi$ with a $78.5 \mathrm{~mm}^{2}$ area. The electrode thickness was within the range of $40-50 \mu \mathrm{m}$. The electrodes were further sintered at $650^{\circ} \mathrm{C}$ under vacuum for $3 \mathrm{~h}$ and then pressed at $200 \mathrm{kgf} \mathrm{cm}^{-2}$. The specific capacity was calculated according to the weight of $S i$ in the composite particles.

Electrochemical testing of the composite electrodes was conducted using two-electrode test coin cells (2032-type, Housen, Japan) with caulked metal cups and a gasket to hold the electrode assembly and a separator. The coin cells were assembled in an Ar-filled glove box using a $1 \mathrm{M}$ lithium hexafluorophosphate $\left(\mathrm{LiPF}_{6}\right)$ electrolyte in a mixed solution of ethylene carbonate (EC), diethylene carbonate (DEC), and dimethyl carbonate (DMC) $(60: 25: 15, \mathrm{v} / \mathrm{v})$. An Al foil coated with a $\mathrm{LiCoO}_{2}$ film ( $320 \mu$ m thickness) with a capacity of $4.5 \mathrm{mAh} \mathrm{cm}^{-2}$ was employed as the cathode counter electrode, with a polyethylene/polypropylene/polyethylene multistacked film separator ( $40 \mu \mathrm{m}$ thickness). The cathode electrode, separator, and anode electrode were not pressed before assembly in the test coin cell and were held in place by a leaf spring. The electrochemical performance of these two-electrode test coin cells was evaluated using a constant current charge-discharge cycling test in the voltage range of $1.6-4.2 \mathrm{~V}$, with a current density of $0.1 \mathrm{~mA} \mathrm{~cm}^{-2}$ at room temperature.

\section{Results and Discussion}

2.1. Characterization of the Composite. In this study, we obtained composite particles by grinding $\mathrm{Si}, \mathrm{H}_{2} \mathrm{O}$, and $\mathrm{Cu}$ (1.88 g Si, $0.12 \mathrm{~g} \mathrm{H}_{2} \mathrm{O}$, and $0.28 \mathrm{~g} \mathrm{Cu}$; Table 1 ) in a planetary 
TABLE 1: Amounts of $\mathrm{Si}, \mathrm{H}_{2} \mathrm{O}$, and $\mathrm{Cu}$ used in the grinding process.

\begin{tabular}{lcccccccc}
\hline $\mathrm{Si}: \mathrm{O}=10: X$ & 0 & 0.33 & 0.5 & 0.75 & 1 & 1.3 & 1.5 & 3 \\
\hline $\mathrm{Si}(\mathrm{g})$ & 2.0 & 1.95 & 1.94 & 1.91 & 1.88 & 1.84 & 1.82 & \\
$\mathrm{H}_{2} \mathrm{O}(\mathrm{g})$ & 0 & 0.05 & 0.06 & 0.09 & 0.12 & 0.16 & 0.18 & 0.32 \\
$\mathrm{Cu}(\mathrm{g})$ & 0.28 & 0.28 & 0.28 & 0.28 & 0.28 & 0.28 & 0.28 & 0.28 \\
\hline
\end{tabular}

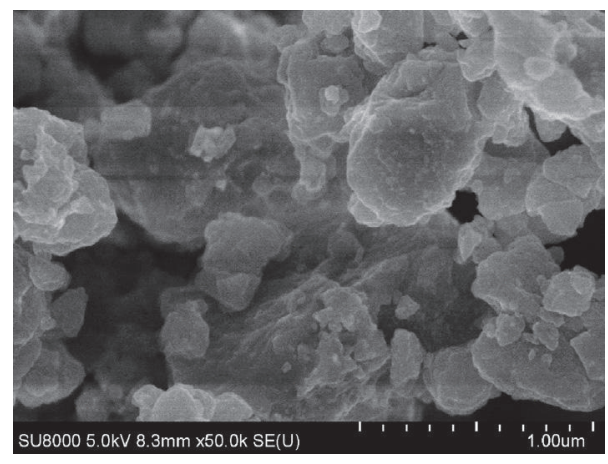

FIGURE 2: SEM image of microscale composite particles formed by grinding $\mathrm{Si}, \mathrm{H}_{2} \mathrm{O}$, and $\mathrm{Cu}$.

ball mill machine for a total of $3 \mathrm{~h}$ to obtain a homogeneous distribution of each component $(\mathrm{Si}, \mathrm{O}$, and $\mathrm{Cu})$ in the composite. The molar ratio of $\mathrm{Si}: \mathrm{O}$ in the composite was controlled at $10: 1$. The SEM images in Figure 2 reveal the composite particles obtained after grinding $\mathrm{Si}, \mathrm{H}_{2} \mathrm{O}$, and $\mathrm{Cu}$. The composite particles, which are similar in size to the bare Si particle, appear to have small particles attached along their circumferences. The composite particles were from 0.1 to $3.8 \mu \mathrm{m}$ in size with an existence probability of $95 \%$, and the medium diameter was $1.6 \mu \mathrm{m}$. Further, the average tapping density measured for the prepared sample was $2.19 \mathrm{~g} \mathrm{~cm}^{-3}$, which is comparable to the tapping density of $\mathrm{Si}$ (approximately $2.3 \mathrm{~g} \mathrm{~cm}^{-3}$ ).

An electrode coated with a mixture of composite particles, conductive materials, and a binder was cut using a Ga FIB to analyse electrode cross sections by STEM. The dark field image of the sliced anode electrode (Figure 3) shows dark grey areas corresponding to $\mathrm{Si}$ components and white areas corresponding to $\mathrm{Cu}$ or $\mathrm{Cu}$ components. Thus, it was revealed that the $\mathrm{Si}$ composites were homogeneously mixed with $\mathrm{Cu}$ materials. Punctate white regions were also observed in the composite materials, and we surmised that the composites were synthesized from a mixture of materials based on $\mathrm{Si}, \mathrm{H}_{2} \mathrm{O}$, and $\mathrm{Cu}$. EDX was used to measure the atomic distribution of $\mathrm{Si}$, oxides, and $\mathrm{Cu}$ (Figure 4) in the composite. These results show that the material obtained following the grinding process contains both $\mathrm{Si}$ and $\mathrm{Cu}$ nanograins.

Figure 5 shows a high-resolution STEM image at $2000 \mathrm{~K}$ magnification of the area of the composite indicated by a white circle in the inset. The sample composition was observed as aggregates of nanoscale grains based on individual $\mathrm{Si}$ and $\mathrm{Si}-\mathrm{Cu}$ composite materials. The bright grey areas, indicated by white arrows in Figure 5, are occupied by $\mathrm{Si}$

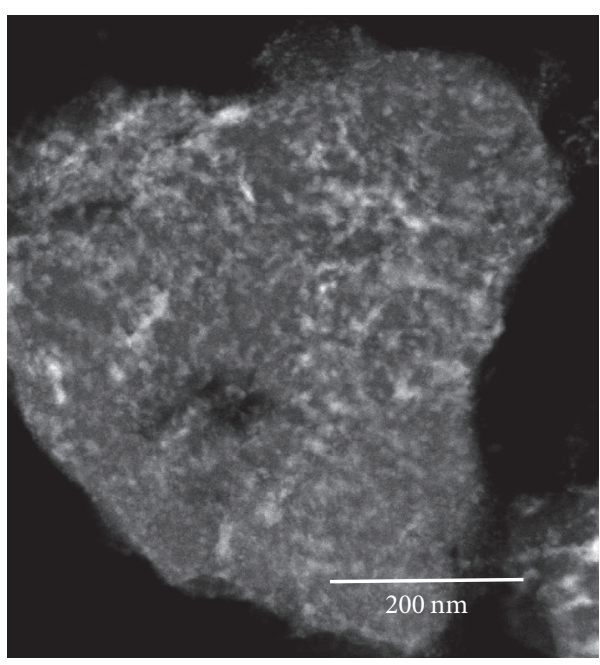

FIGURE 3: STEM cross-sectional dark field image of a compositecoated anode cut using a Ga FIB.

materials, whereas the dark grey areas, indicated by black arrows, contain $\mathrm{Cu}$ materials. The directions of these arrows indicate the orientation of each $\mathrm{Si}$ or $\mathrm{Cu}$ crystal lattice. Thus, high-resolution STEM imaging confirms that each grain has a random crystal orientation and that the composite mainly comprises poly- $\mathrm{Si}$ and $\mathrm{Si}-\mathrm{Cu}$ composite nanograins.

The crystallization state of the ground composite was examined using XRD, as shown in Figure 6. Only Si and $\mathrm{Cu}$ particles were observed before the grinding process, whereas in the composite obtained after grinding, crystal patterns were observed that correspond to $\mathrm{Si}$ and $\mathrm{Cu}_{3} \mathrm{Si}$ as a $\mathrm{Si}-\mathrm{Cu}$ alloy [19]. Most oxygen atoms from $\mathrm{H}_{2} \mathrm{O}$ were transferred to $\mathrm{Si}$ by the grinding process; on the other hand, $\mathrm{Cu}$ did not react with $\mathrm{H}_{2} \mathrm{O}$ directly. These results confirm that the material obtained by grinding is a composite constructed of aggregated nanoscale grains of $\mathrm{Si}$, Si oxidation materials, and $\mathrm{Cu}_{3}$ Si materials.

The distribution of oxides in the composite was measured using EELS. The EELS map obtained from STEM images is shown in Figure 7. Owing to oxidation reactions initiated by the grinding process, most oxygen atoms from $\mathrm{H}_{2} \mathrm{O}$ were incorporated with Si into Si oxides. The EELS map in Figure 7, which is constructed from the spectral data at energy losses between 532 and $570 \mathrm{eV}$, implies that the distribution of oxide species, indicated by white dots, is not homogeneous in the composite. Thus, oxide species are concentrated near the surface of the composite particle, although some oxides also exist inside the particle.

The Si oxidation number of the composite particles was determined using high-resolution Si2p XPS spectroscopy. 


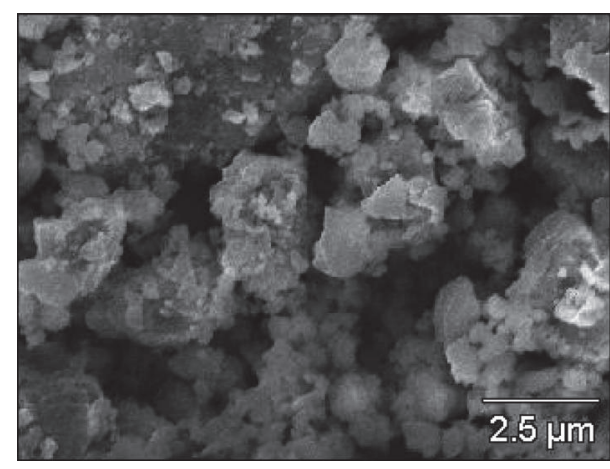

(a)

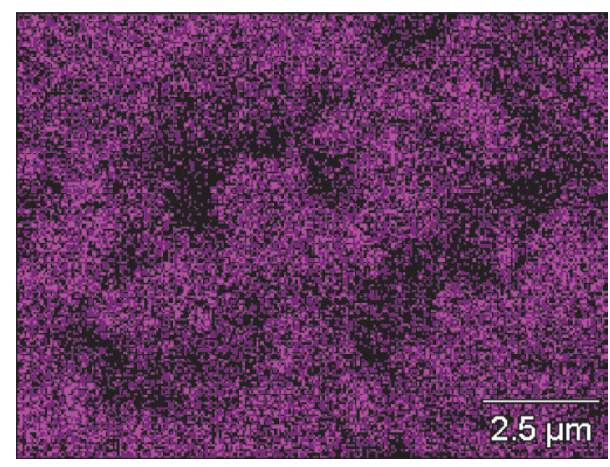

(c)

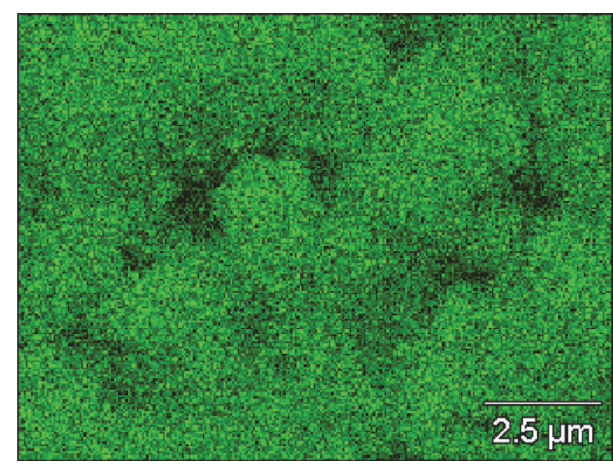

(b)

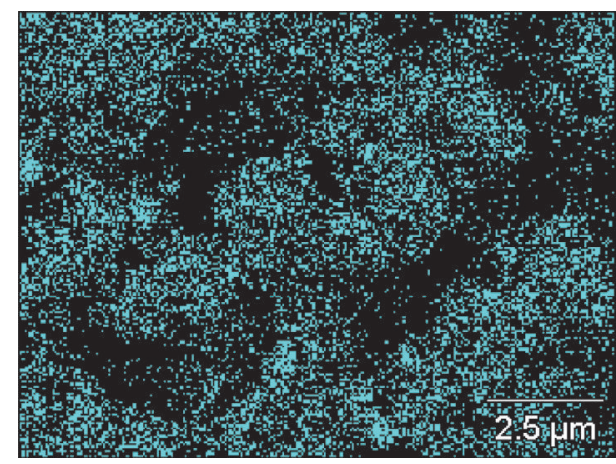

(d)

FIGURE 4: (a) STEM bright field image of the composite material and corresponding EDX distribution maps for (b) Si, (c) O, and (d) Cu.

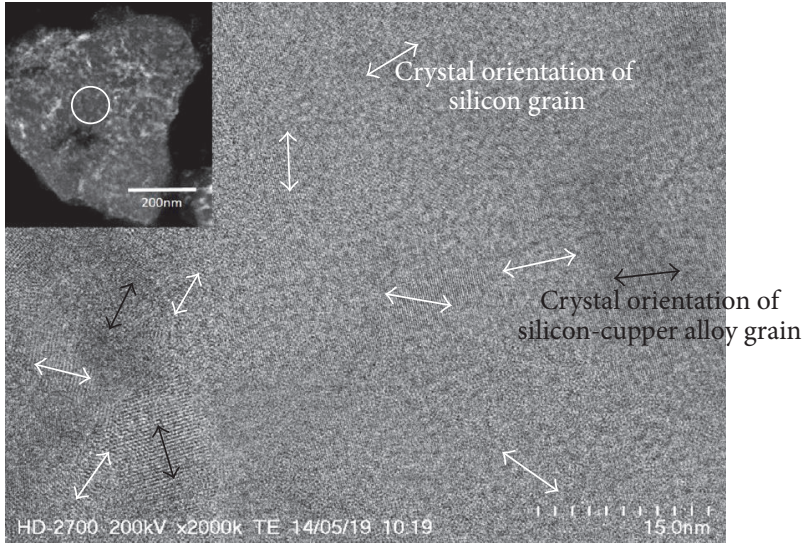

FIGURE 5: High-resolution STEM image of the composite (in the area indicated by a white circle in the inset) showing the presence of $\mathrm{Si}$ and $\mathrm{Si}-\mathrm{Cu}$ alloy materials.

The binding energies of the peaks in the XPS spectra were extrapolated by fitting with the Voigt profile [20-22]. The peak corresponding to carbon contaminants was employed as a reference for the binding energy. The XPS results shown in Figure 8 indicate that the composite contains a variety of $\mathrm{Si}$ ions with different oxidation numbers. The Si $2 p$ peaks located at higher binding energies $(\sim 100-104 \mathrm{eV})$ mainly correspond to $\mathrm{Si}$-suboxide species: $\mathrm{Si}^{4+}, \mathrm{Si}^{3+}, \mathrm{Si}^{2+}$,

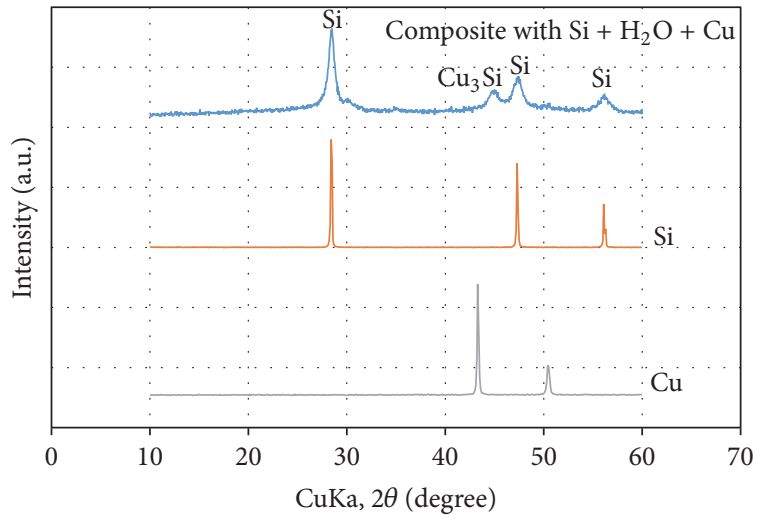

FIgURE 6: XRD patterns of the $\mathrm{Si}, \mathrm{H}_{2} \mathrm{O}$, and $\mathrm{Cu}$ composite after the grinding process and $\mathrm{Si}$ and $\mathrm{Cu}$ particles before the grinding process.

and $\mathrm{Si}^{1+}$. The content ratios of the different $\mathrm{Si}$ ions in the composite particles were calculated by deconvolution of the peak, which was calibrated against the $\mathrm{C} 1 s$ signal. In addition, each $\mathrm{Si}$ oxidation number was evaluated by calculating the chemical shift distribution based on the results shown in Figure 8. Si in the composite particles is mainly $\mathrm{Si}^{0}(\mathrm{Si})$; however, the distribution of the binding energies indicates that the composite also contains some oxidized Si species: $\mathrm{Si}^{4+}, \mathrm{Si}^{3+}, \mathrm{Si}^{2+}$, and $\mathrm{Si}^{1+}$. This finding confirms the existence of a semisilicate, similar to Si monoxide, near the surface 


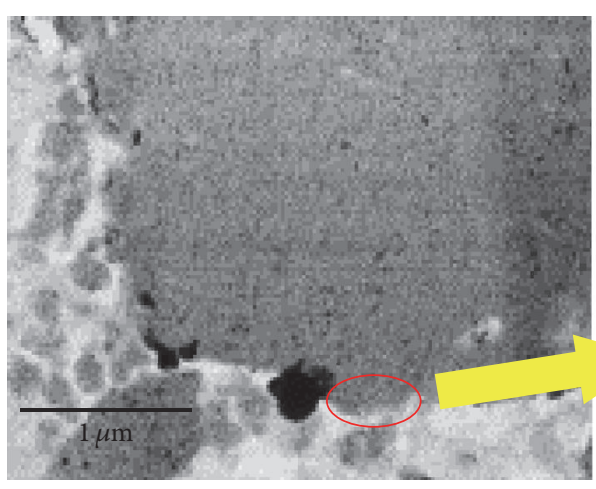

(a)

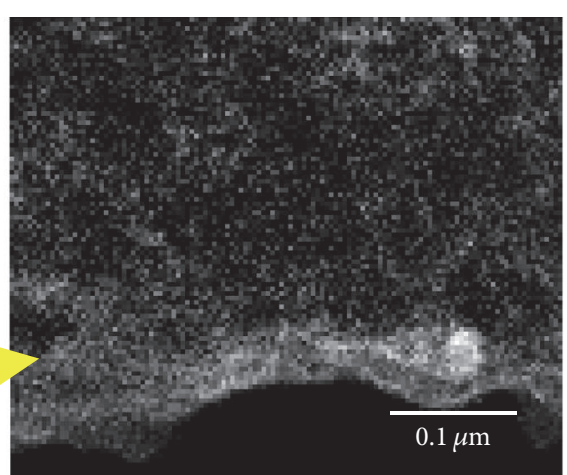

(b)

FIGURE 7: (a) STEM bright field image of the composite and (b) EELS map of the distribution of oxides in the composite for the area in the red circle in (a).

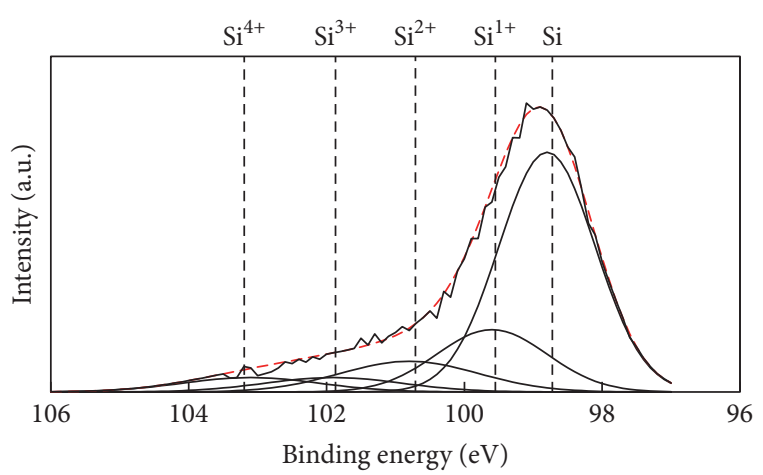

FIGURE 8: Si2p XPS spectrum of the composite.

of the particles. Approximately $75 \%$ of the XPS spectrum corresponds to $\mathrm{Si}$ and $\mathrm{Si}^{1+}$, suggesting that the composite has a strong metallic character. Nearly $80 \%$ of all other oxidized species have oxidation numbers of $\mathrm{Si}^{2+}$ and $\mathrm{Si}^{3+}$. The formation of Si monoxide or semimonoxide is expected owing to the controlled amount of $\mathrm{H}_{2} \mathrm{O}$ added before the grinding process. These findings are evidence of the synthesis of Si monoxide or submonoxide, which are potentially useful as active materials in LIBs, based on oxidization reactions during grinding with $\mathrm{H}_{2} \mathrm{O}$.

2.2. Electrochemical Performance of the Composite. The electrochemical performance of the composite anode was evaluated in a 2032-type test coin cell using a constant current charge-discharge cycling test in the voltage range of 1.60$4.16 \mathrm{~V}$ with a current density of $0.1 \mathrm{~mA} \mathrm{~cm}^{-2}$ at room temperature. The state of charge was controlled at $100 \%$ in this study. As shown in Figure 9, the 1st charge-discharge capacity of the composite is more favourable than that using Si particles as a reference anode. The capacity was calculated using the weight of Si included in the anode of the coin cell. The 1st charge and discharge capacities for the composite were 3384 and $3160 \mathrm{mAh} \mathrm{g}^{-1}$, respectively, whereas those for Si particles were 3871 and $3198 \mathrm{mAh} \mathrm{g}^{-1}$, respectively.

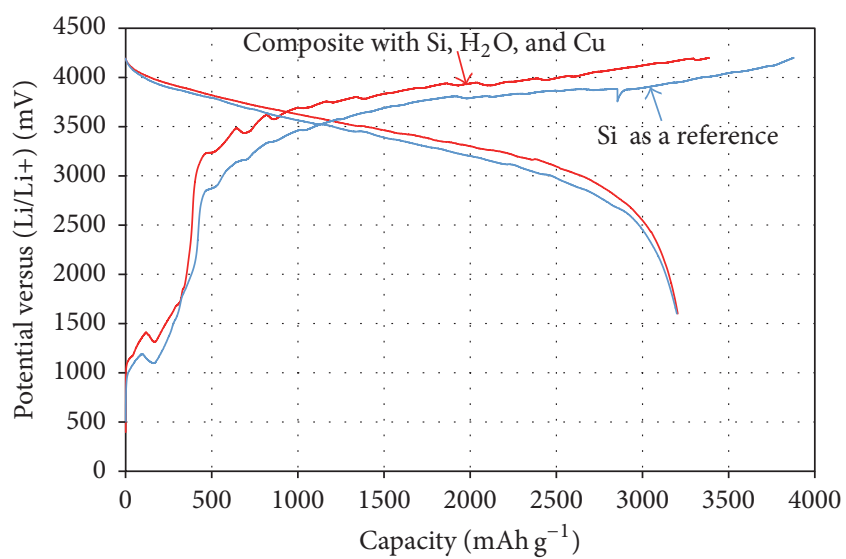

FIGURE 9: Charge-discharge capacity profiles of the composite anode (red) and a Si particle reference (blue).

The recharging capacity results indicate that the charge and reversible discharge capacities depend on the composition of the active material. The composite obtained by grinding $\mathrm{Si}, \mathrm{H}_{2} \mathrm{O}$, and $\mathrm{Cu}$ demonstrated a 1st coulombic efficiency of $94.1 \%$ (Figure 10, red), whereas a 1st coulombic efficiency of $82.9 \%$ was observed when the anode only contained Si particles (Figure 10, blue). When the active material only contains $\mathrm{Si}$, the 1st coulombic efficiency approaches $83 \%$ owing to formation of an irreversible solid electrolyte interphase (SEI), a chemical compound consisting of $\mathrm{Li}, \mathrm{Si}$, and solvent of electrolyte, on each Si particle, which does not work as an active material $[1,3]$. Furthermore, Si crystals form amorphous or quasiamorphous Si phases after discharging Li ions, which have a lower capacity than the theoretical capacity of crystalline Si [5].

The composite produced by grinding $\mathrm{Si}, \mathrm{H}_{2} \mathrm{O}$, and $\mathrm{Cu}$ was successfully employed as an anode to occlude $\mathrm{Li}$ ions. The composite is constructed of aggregates of $\mathrm{Si}$, Si oxidation products, and $\mathrm{Cu}_{3} \mathrm{Si}$ nanoscale particles, as indicated in Figure 5. We surmise that the $\mathrm{Si}$ nanoscale grains in the composite help to occlude $\mathrm{Li}$ ions with high coulombic efficiency during the first charge-discharge cycle; moreover, 


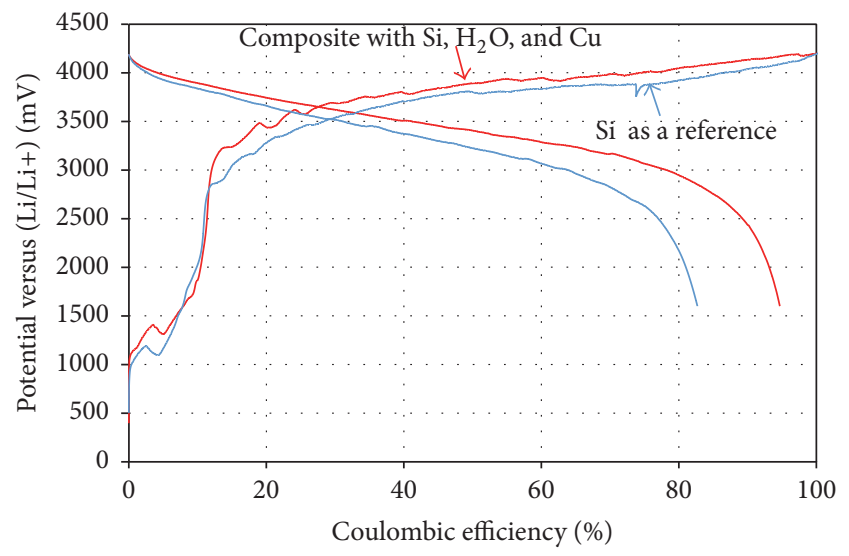

FIGURE 10: First coulombic efficiencies of the composite anode (red) and a Si particle reference (blue).

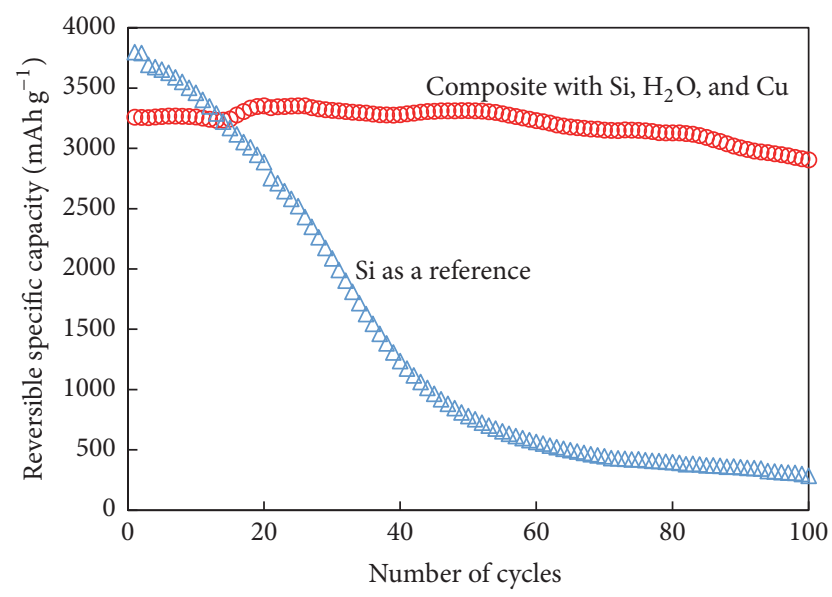

FIGURE 11: Cycling characteristics of the composite anode (red) and a Si particle reference (blue).

the $\mathrm{Cu}_{3} \mathrm{Si}$ nanoscale grains act as an electrically conductive material. Further, to obtain good coulombic efficiency, the mixture of Si and Si monoxide prevents irreversible formation of an SEI [23-25]. In such mixtures, the optimized recharging efficiency and the conductivity of Si monoxide are lower than those of other Si oxides [26].

The cycling characteristics of the composite anode and a reference anode employing only Si particles are compared in Figure 11 . The composite demonstrated a reversible capacity of over $3000 \mathrm{mAh} \mathrm{g}^{-1}$ after 100 cycles. Moreover, the capacity retention was over $99.9 \%$ for the 2nd cycle and $91.6 \%$ for the 100th cycle (Figure 11). In contrast, the bare Si particle anode had a low capacity retention of less than $50 \%$ over 40 cycles.

The monoxide or submonoxide Si species in the composite form near the surface, as shown in Figure 6. Thus, the structure of the composite was visualized as a $\mathrm{Si}$ active material covered by an oxide film. The optimization of the cycling characteristics by covering Si particles with an oxide film has been reported $[26,27]$. The capacity retention was clearly found to be optimized by covering the active materials of the LIB anode with a thin film coating. It is believed

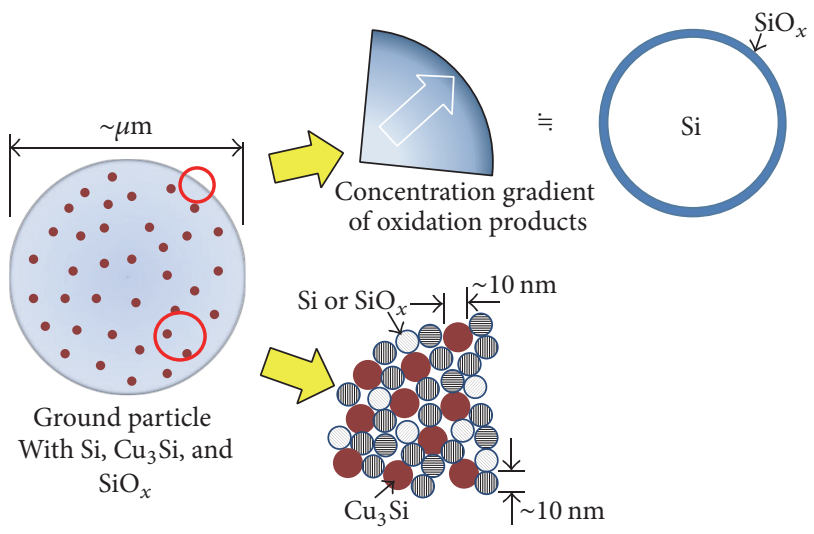

FIGURE 12: Schematic illustration of the composite formed by grinding $\mathrm{Si}, \mathrm{H}_{2} \mathrm{O}$, and $\mathrm{Cu}$. The composite can be modelled as an aggregate of $\mathrm{Si}, \mathrm{Cu}_{3} \mathrm{Si}$ nanoscale grains, and $\mathrm{Si}$ oxidation products near the surface, similar to a Si particle covered with a Si oxide film.

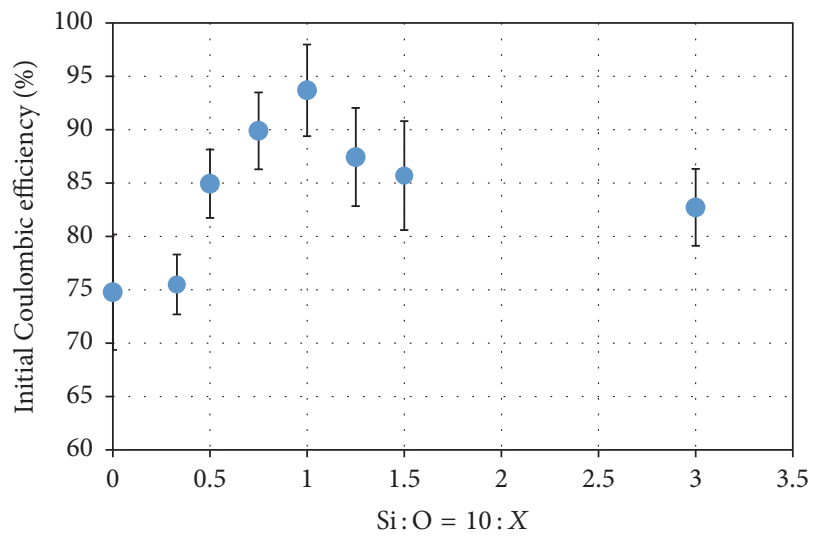

FIGURE 13: Change in initial coulombic efficiency with oxygen (as $\mathrm{H}_{2} \mathrm{O}$ ) addition ratio.

that the film covering each Si particle plays a buffering role by preventing cracking following drastic changes in volume with numerous repetitions of the charge-discharge cycle. Based on our results, the composite has a structure consisting of aggregated $\mathrm{Si}, \mathrm{Cu}$ nanoscale grains, and $\mathrm{Si}$ oxidation products, which accumulate as Si oxides at the surface of the composite and allow for optimization of the electrochemical characteristics of LIB cells, as shown in Figure 12.

The prepared composite sample exhibited nanostructures corresponding to both a $\mathrm{Si}$ matrix and $\mathrm{Cu}_{3} \mathrm{Si}$ grains, which may be partly responsible for the improvement in battery performance, as reported in other studies on the preparation of nanostructured samples by various methods. However, we consider that there are other possible reasons for the improved performance of our composite sample. Notably, the extent of oxidization of the Si grains played an important role in increasing the coulombic efficiency, as revealed when we varied the ratio of $\mathrm{H}_{2} \mathrm{O}$ to $\mathrm{Si}$ in the sample. Figure 13 shows the relationship between the initial coulombic efficiency and the molar ratio of $\mathrm{Si}$ to $\mathrm{H}_{2} \mathrm{O}$ used during composite preparation. Without added $\mathrm{H}_{2} \mathrm{O}$, the coulombic efficiency was as low as 
$75 \%$, but this value increased rapidly to $93.7 \%$ for a $\mathrm{Si}$ to $\mathrm{H}_{2} \mathrm{O}$ ratio of $10: 1$. Further increasing the amount of $\mathrm{H}_{2} \mathrm{O}$ led to a decrease in the coulombic efficiency. We postulated that higher amounts of $\mathrm{H}_{2} \mathrm{O}$ during the mechanochemical reaction between $\mathrm{Si}, \mathrm{H}_{2} \mathrm{O}$, and $\mathrm{Cu}$ would result in the production of a highly oxidized state of $\mathrm{Si}$, with a higher ratio of $\mathrm{SiO}_{2}$ in the obtained composite. Highly oxidized $\mathrm{Si}$ species such as $\mathrm{SiO}_{2}$ tend to form stable $\mathrm{Li}$ silicates during the battery charging operation. When a $\mathrm{Si}$ to $\mathrm{H}_{2} \mathrm{O}$ ratio of $10: 1$ was used for sample preparation, as shown in Figures $3-8$, the obtained reaction product was $\mathrm{SiO}_{x}$, where $x$ is around 1 and much smaller than 2, as XPS analysis showed the formation of an amorphous layer around the crystalline $\mathrm{Si}$ grains. During lithiation, $\mathrm{SiO}_{x}$ with a low oxidation state will have a low tendency to react with $\mathrm{Li}$ to form silicates. On the other hand, the large increase in conductivity reported to be associated with low oxidation states of $\mathrm{Si}$ [26] will make the amorphous $\mathrm{SiO}_{x}$ layer more conductive than the $\mathrm{Si}$ matrix grains. Moreover, this layer acts as a physical buffer to reduce volume changes, thereby increasing efficiency.

\section{Experimental}

3.1. Synthesis of Composites of $\mathrm{Si}, \mathrm{H}_{2} \mathrm{O}$, and $\mathrm{Cu}$. As an excellent conductor, $\mathrm{Cu}_{3} \mathrm{Si}$ has been widely studied for the improvement of Si anode performance through various modifications, such as coated layers on Si grains, and increased cycling efficiencies have been reported [28-31]. As shown in Figure $3, \mathrm{Cu}_{3} \mathrm{Si}$ nanoparticles with sizes of less than $10 \mathrm{~nm}$ are dispersed uniformly among the Si grains in our composite, which increases its conductivity. In addition to contributing to electronic conductivity, $\mathrm{Cu}_{3} \mathrm{Si}$ may also serve as a good catalyst for increasing the cycling efficiency. There have been several reports on the catalytic effects of $\mathrm{Cu}_{3} \mathrm{Si}$ in producing chlorosilanes from the reaction between $\mathrm{CH}_{3} \mathrm{Cl}$ and $\mathrm{Si}$ [32]. Harper et al. have reported room-temperature oxidation of $\mathrm{Si}$ catalysed by $\mathrm{Cu}_{3} \mathrm{Si}$ [33]. These studies indicate the high ability of $\mathrm{Cu}_{3} \mathrm{Si}$ to catalyse the oxidation of $\mathrm{Si}$ to form chlorides or oxides. Although there have been no direct studies reporting the oxidation of $\mathrm{Li}$ silicides in anode materials, we believe that, in our prepared sample, the $\mathrm{Cu}_{3} \mathrm{Si}$ nanoparticles dispersed uniformly around the $\mathrm{Si}$ grains, which exist as Li silicides after charging, will catalyse the oxidation of Li silicides and facilitate Li release, so that the rate of capacity fading is reduced. In addition to catalysis by $\mathrm{Cu}_{3} \mathrm{Si}$, the synergistic effects of the nanostructure of $\mathrm{Si}$ grains and the amorphous oxidized layers formed around the Si grains are considered to contribute to the observed high performance, with a capacity of over $3000 \mathrm{mAh} \mathrm{g}^{-1}$ maintained after 100 cycles. The synergistic effects result from the mechanochemical approach, which is generally studied for stoichiometric reactions. However, in this case, nonstoichiometric ratios of $\mathrm{H}_{2} \mathrm{O}$ and $\mathrm{Cu}$ were used to successfully prepare $\mathrm{Si}$ anode materials, expanding our understanding of mechanochemical phenomena.

\section{Conclusion}

Though it is necessary to employ $\mathrm{Si}$ as an active material to achieve both high charge and good cycling characteristics for charge-discharge performance, it is difficult to control $\mathrm{Si}$ active materials. We created a composite of active materials as an anode electrode for LIBs by compounding Si particles with $\mathrm{H}_{2} \mathrm{O}$ and $\mathrm{Cu}$ particles using a grinding process. Oxidationreduction reactions between $\mathrm{Si}$ and $\mathrm{H}_{2} \mathrm{O}$ were activated by this process, resulting in $\mathrm{Si}$ oxidation. Thus, a composite containing aggregates of $\mathrm{Si}$, Si oxidation products, and $\mathrm{Cu}_{3} \mathrm{Si}$ nanoscale grains was achieved.

The $\mathrm{Si}$ oxidation number of the $\mathrm{Si}$ oxidation products could be controlled by the amount of $\mathrm{H}_{2} \mathrm{O}$ added during grinding. Si monoxide was located near the surface of the composite, as revealed by EELS and XPS measurements. Therefore, the composite acts as an active material with high capacity and excellent charge-discharge properties over many cycles. Thus, we consider that further drastic improvement may be obtained from synergy effects when two or more actions are simultaneously introduced with only one operation. And this synthesis method for new anode materials and the battery, which has this anode, a commercial cathode, and an electrolyte, will be available for practical use in the commercial battery market.

While optimizing our treatment conditions for preparation of the $\mathrm{Si}$ composite, we are considering different applications of nonstoichiometric reactions to other similarly intricate issues. For example, we expect to be able to synthesis a cathode composite having more than three $\mathrm{Li}$ atoms in a molecule via the grinding process.

\section{Conflicts of Interest}

The authors declare that they have no competing interests.

\section{Acknowledgments}

The authors kindly thank DOWA Holdings Corporation for their help in the construction and electrochemical measurements of the composite employed in this study. The authors would like to thank Editage (https://www.editage.jp) for English language editing.

\section{References}

[1] A. Netz, R. A. Huggins, and W. Weppner, "The formation and properties of amorphous silicon as negative electrode reactant in lithium systems," Journal of Power Sources, vol. 119-121, pp. 95-100, 2003.

[2] K. Peng, J. Jie, W. Zhang, and S.-T. Lee, "Silicon nanowires for rechargeable lithium-ion battery anodes," Applied Physics Letters, vol. 93, no. 3, Article ID 033105, 2008.

[3] Y. Zhang, Z. Fu, and Q. Qin, "Microstructure and Li alloy formation of nano-structured amorphous $\mathrm{Si}$ and $\mathrm{Si} / \mathrm{TiN}$ composite thin film electrodes," Electrochemistry Communications, vol. 6, no. 5, pp. 484-491, 2004.

[4] D. Munaò, M. Valvo, J. Van Erven, E. M. Kelder, J. Hassoun, and S. Panero, "Silicon-based nanocomposite for advanced thin film anodes in lithium-ion batteries," Journal of Materials Chemistry, vol. 22, no. 4, pp. 1556-1561, 2012.

[5] H.-Y. Lee and S.-M. Lee, "Carbon-coated nano-Si dispersed oxides/graphite composites as anode material for lithium ion 
batteries," Electrochemistry Communications, vol. 6, no. 5, pp. 465-469, 2004.

[6] M. Mamiya, H. Takei, M. Kikuchi, and C. Uyeda, "Preparation of fine silicon particles from amorphous silicon monoxide by the disproportionation reaction," Journal of Crystal Growth, vol. 229, no. 1, pp. 457-461, 2001.

[7] K. Tahara, F. Iwasaki, T. Tamachi, and T. Sakai, The 38th Battery Symposium in Osaka, 1997.

[8] J. R. Dahn, S. Trussler, T. D. Hatchard et al., "Economical sputtering system to produce large-size composition-spread libraries having linear and orthogonal stoichiometry variations," Chemistry of Materials, vol. 14, no. 8, pp. 3519-3523, 2002.

[9] M. D. Fleischauer, T. D. Hatchard, G. P. Rockwell et al., "Design and testing of a 64-channel combinatorial electrochemical cell," Journal of the Electrochemical Society, vol. 150, no. 11, pp. A1465A1469, 2003.

[10] V. K. Cumyn, M. D. Fleischauer, T. D. Hatchard, and J. R. Dahn, "Design and testing of a low-cost multichannel pseudopotentiostat for quantitative combinatorial electrochemical measurements on large electrode arrays," Electrochemical and Solid-State Letters, vol. 6, no. 6, pp. E15-E18, 2003.

[11] H. Yamamoto, M. Miyachi, and H. Kawai, "Abstracts of the Electrochemical Society of Japan 2004 Spring Meeting," Yokohama, pp. 204, 2004.

[12] T. Morita and N. Takami, "Nano Si cluster- $\mathrm{SiO}_{x}-\mathrm{C}$ composite material as high-capacity anode material for rechargeable lithium batteries," Journal of The Electrochemical Society, vol. 153, no. 2, pp. A425-A430, 2006.

[13] M. Yamada, A. Ueda, K. Matsumoto, and T. Ohzuku, "Siliconbased negative electrode for high-capacity lithium-ion batteries: 'SiO'-carbon composite," Journal of The Electrochemical Society, vol. 158, no. 4, pp. A417-A421, 2011.

[14] Y. Ren, J. Ding, N. Yuan, S. Jia, M. Qu, and Z. Yu, "Preparation and characterization of silicon monoxide/graphite/carbon nanotubes composite as anode for lithium-ion batteries," Journal of Solid State Electrochemistry, vol. 16, no. 4, pp. 1453-1460, 2012.

[15] N. Dimov, S. Kugino, and M. Yoshio, "Mixed silicon-graphite composites as anode material for lithium ion batteries: influence of preparation conditions on the properties of the material," Journal of Power Sources, vol. 136, no. 2, pp. 108-114, 2004.

[16] M. Yoshio, T. Tsumura, and N. Dimov, "Silicon/graphite composites as an anode material for lithium ion batteries," Journal of Power Sources, vol. 163, no. 1, pp. 215-218, 2006.

[17] J.-H. Kim, H.-J. Sohn, H. Kim, G. Jeong, and W. Choi, "Enhanced cycle performance of $\mathrm{SiO}-\mathrm{C}$ composite anode for lithium-ion batteries," Journal of Power Sources, vol. 170, no. 2, pp. 456-459, 2007.

[18] N. Shimoi, Z. Qiwu, S. Bahena-Garrido, and Y. Tanaka, "Mechanochemical approaches to employ silicon as a lithium-ion battery anode," AIP Advances, vol. 5, no. 5, Article ID 057142, 2015.

[19] Y. Tanaka, Q. Zhang, and F. Saito, "Mechanochemical dechlorination of trichlorobenzene on oxide surfaces," Journal of Physical Chemistry B, vol. 107, no. 40, pp. 11091-11097, 2003.

[20] Y. Hatanaka, S. Wickramanayaka, A. Matsumoto, Y. Nakanishi, and A. M. Wrobel, "Preparation of silicon based widegap semiconductor film from organo-silicon by using remote plasma CVD method," Bulletin of the Research Institute of Electronics, Shizuoka University, vol. 29, pp. 87-94, 1994.

[21] F. J. Himpsel, F. R. McFeely, A. Taleb-Ibrahimi, J. A. Yarmoff, and G. Hollinger, "Microscopic structure of the $\mathrm{SiO}_{2} / \mathrm{Si}$ interface," Physical Review B, vol. 38, no. 9, pp. 6084-6096, 1988.
[22] F. Jolly, F. Rochet, G. Dufour, C. Grupp, and A. Taleb-Ibrahimi, "Oxidized silicon surfaces studied by high resolution Si 2p corelevel photoelectron spectroscopy using synchrotron radiation," Journal of Non-Crystalline Solids, vol. 280, no. 1-3, pp. 150-155, 2001.

[23] M. Miyachi, H. Yamamoto, and H. Kawai, "Electrochemical properties and chemical structures of metal-doped $\mathrm{SiO}$ anodes for Li-ion rechargeable batteries," Journal of the Electrochemical Society, vol. 154, no. 4, pp. A376-A380, 2007.

[24] M. Miyachi, H. Yamamoto, H. Kawai, T. Ohta, and M. Shirakata, "Analysis of $\mathrm{SiO}$ anodes for lithium-ion batteries," Journal of the Electrochemical Society, vol. 152, no. 10, pp. A2089-A2091, 2005.

[25] Y. Nagao, H. Sakaguchi, H. Honda, T. Fukunaga, and T. Esaka, "Structural analysis of pure and electrochemically lithiated $\mathrm{SiO}$ using neutron elastic scattering," Journal of the Electrochemical Society, vol. 151, no. 10, pp. A1572-A1575, 2004.

[26] I. T. Johansen, "Electrical conductivity in evaporated silicon oxide films," Journal of Applied Physics, vol. 37, no. 2, pp. 499$507,1966$.

[27] N. Shimoi and Y. Tanaka, "Improvement in Si active material particle performance for lithium-ion batteries by surface modification of an inductivity coupled plasma-chemical vapor deposition," Electrochimica Acta, vol. 80, pp. 227-232, 2012.

[28] V. A. Sethuraman, K. Kowolik, and V. Srinivasan, "Increased cycling efficiency and rate capability of copper-coated silicon anodes in lithium-ion batteries," Journal of Power Sources, vol. 196, no. 1, pp. 393-398, 2011.

[29] S. Sim, P. Oh, S. Park, and J. Cho, "Critical thickness of $\mathrm{SiO}_{2}$ coating layer on core@Shell bulk@nanowire Si anode materials for Li-ion batteries," Advanced Materials, vol. 25, no. 32, pp. 4498-4503, 2013.

[30] K.-F. Chiu, K. M. Lin, H. C. Lin, C. H. Hsu, C. C. Chen, and D. T. Shieh, "Electrochemical performances of $\mathrm{Cu}$ nanodots modified amorphous Si thin films for lithium-ion batteries," Journal of the Electrochemical Society, vol. 155, no. 9, pp. A623-A627, 2008.

[31] S. J. Jung, T. Lutz, A. P. Bell, E. K. McCarthy, and J. J. Boland, "Free-standing, single-crystal $\mathrm{Cu}_{3}$ Si nanowires," Crystal Growth and Design, vol. 12, no. 6, pp. 3076-3081, 2012.

[32] D.-H. Sun, B. E. Bent, A. P. Wright, and B. M. Naasz, "Chemistry of the direct synthesis of methylchlorosilanes from methyl + chlorine monolayers on a $\mathrm{Cu}_{3} \mathrm{Si}$ surface," Catalysis Letters, vol. 46, no. 1-2, pp. 127-132, 1997.

[33] J. M. E. Harper, A. Charai, L. Stolt, F. M. d'Heurle, and P. M. Fryer, "Room-temperature oxidation of silicon catalyzed by $\mathrm{Cu}_{3} \mathrm{Si}$," Applied Physics Letters, vol. 56, no. 25, pp. 2519-2521, 1990. 

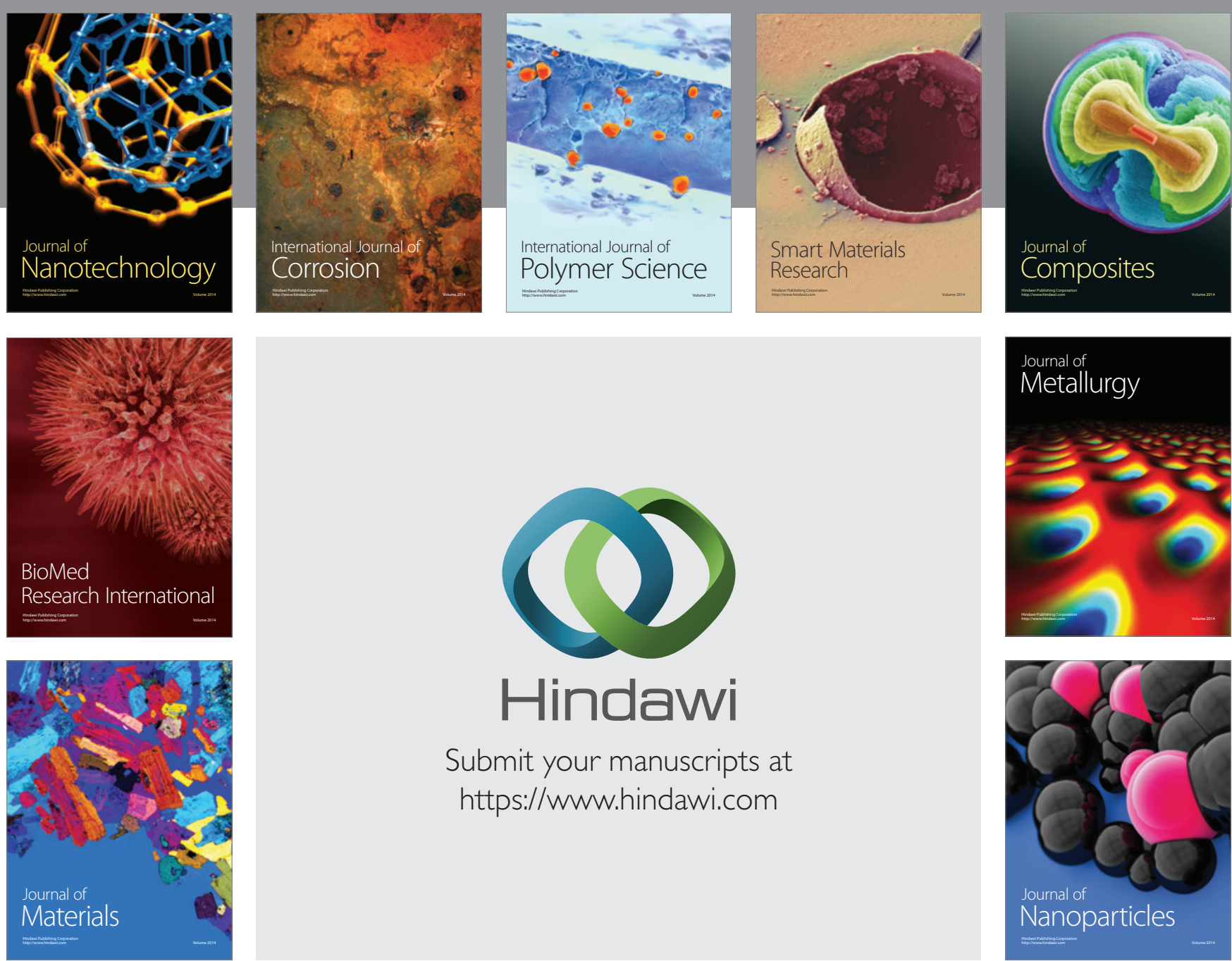

\section{Hindawi}

Submit your manuscripts at

https://www.hindawi.com

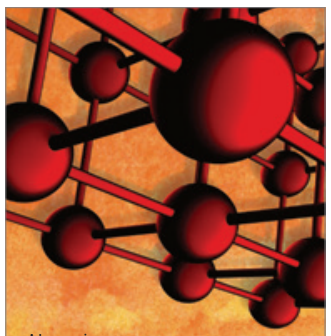

Materials Science and Engineering
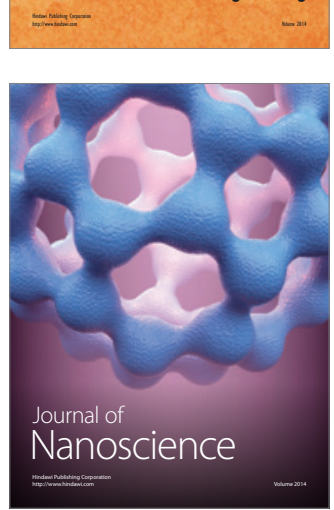
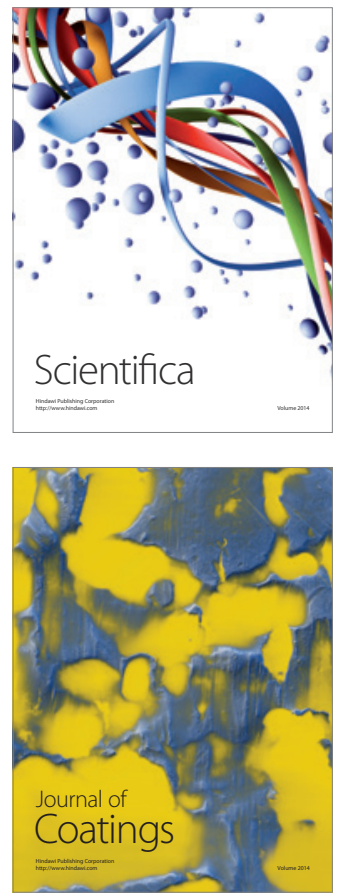
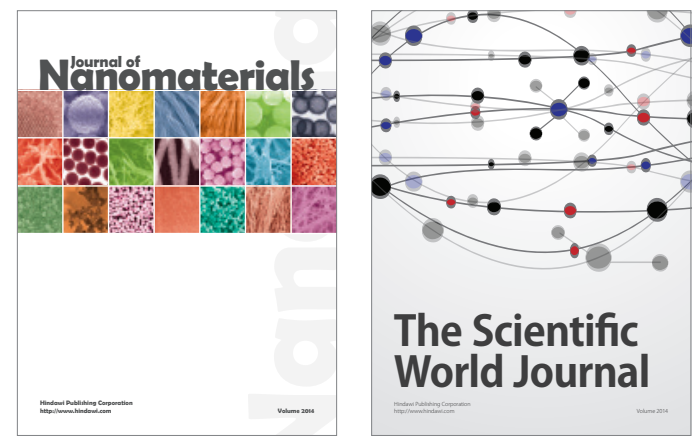

The Scientific World Journal
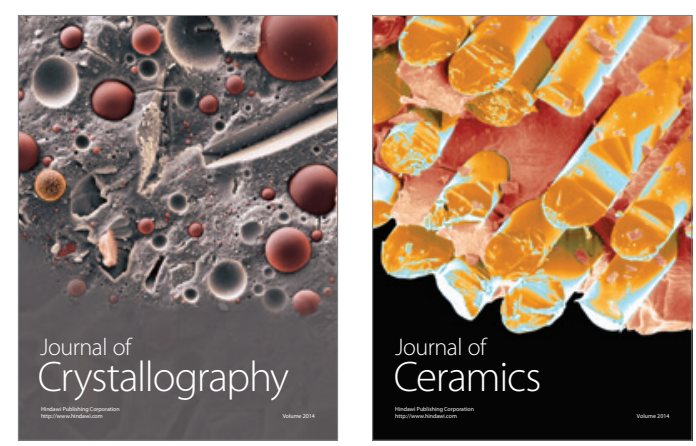
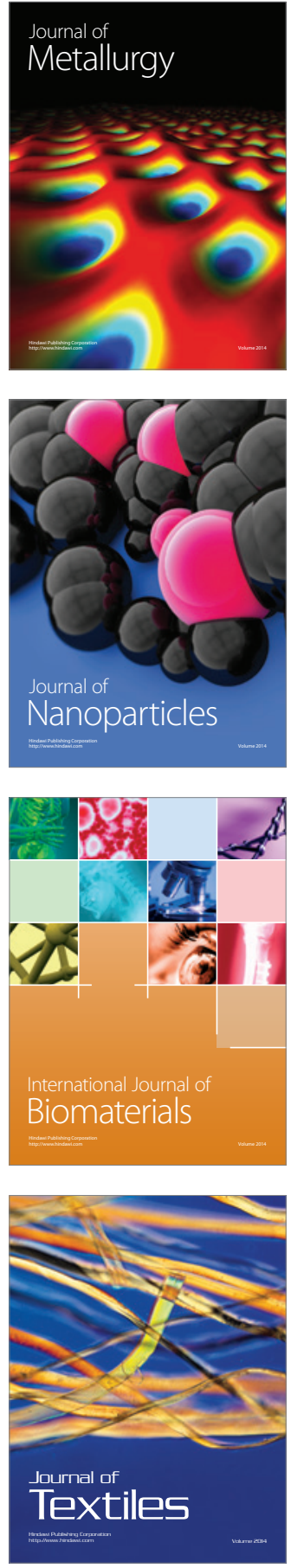